of reaction produced, it is not possible to speak definitely. One of the cases, No. 12, which improved, showed very slight reaction; while one, No. 9 (see illustration), which showed no change mentally, reacted very strongly, although the amount of thyroid given was the same.

It will be seen that none of the eight males became excited during treatment, yet the only cases of permanent improvement occurred in male patients.

On the other hand, seven from out of twelve females (i.e. more than half the number) became excited or showed increased excitement during treatment, but no permanent improvement occurred.

In conclusion, I desire to emphasise the fact that, out of twenty cases treated, two showed permanent improvement, and both of these had previously been regarded as hopeless, on account of the stationary character of their mental condition. Although none of the other cases were so distinctly benefited, it appears to be indicated that this method of treatment should receive a fair trial before any patient is regarded as hopelessly incurable.

\title{
MEDICO-LEGAL NOTES.
}

By H. Nelson Hardy, F.R.C.S.Ed., Divisional Surgeon, Metropolitan Police, London; and Fredk. W. Lowndes, M.R.C.S., Chief Surgeon, Liverpool Police.

Those whose official duties lead them, like the writers of these notes, to spend many hours in the uncongenial atmosphere of criminal courts, whether in London or the provinces, can hardly help observing many little points in regard to medical evidence and the modes of giving it, in which considerable improvement might be effected, if medical men, while still in statu pupillari, or else immediately after qualifying, could be made familiar with the ordinary practice of such courts, by being taken to the old Bailey or the Assize Courts, a few at a time, as the law students are, and afterwards having the more salient points of the cases, from a medical point of view, explained to them by their teachers. There are also many points in medico-legal knowledge on which accumulations of facts are needed to serve as a basis for future advances; and to secure a sufficiently large record of these, we must look, not merely to the lecturers on medical jurisprudence in our schools, but to the practitioners, and especially the youns practitioners scattered over the length and breadth of the land, any one of whom may, soon after commencing practice on his own account, find himself compelled to give evidence in a court of law on matters affecting the life or liberty of one of his fellow-creatures, and also liable to have his knowledge of the 
subject on which he speaks severely tested by the trained intellect of the cross-examining counsel.

A step which has recently been taken by the United Kingdom Police Surgeons' Association, with which the writers are connected, will, it is hoped, have some considerable influence in promoting such an accumulation of facts as is referred to above, with regard to post-mortems, namely, the issue to the members of the Association of a form for recording with precision the results of autopsies made by them as police surgeons $;^{1}$ for it has been found in some places by experts, sent down by the Treasury in cases of murder or manslaughter, that occasionally great laxity prevails both in making and also in recording the results of these examinations; and sometimes not only has the examination made been valueless, but the body has been spoiled for any further use.

In these notes, however, we propose to deal rather with matters which, though apparently of minor importance, have considerable influence in enabling the medical witness to give evidence with comfort to himself, and also so as to produce a favourable impression upon judge and jury.

1. The first point upon which we would lay stress is the importance of accuracy. The salutary rule in the Metropolitan Police district, that whenever a police surgeon is summoned to any important case he is to make a note of what he observes at the time in his notebook, might very well be adopted by all whose duties lead them to give evidence in criminal cases, since recollections of facts are apt to fade from the mind in the course of weeks, or it may be months, which elapse between the occurrence and the trial. In cases of homicide or rape, the date and hour of the first call should always be noted. If this has been done at the time, no objection will be raised to the witness refreshing his memory by having his notebook before him while giving evidence.

2. A second point is that, in his interpretation of medical facts, the witness should observe the strictest impartiality, neither, on the one hand, straining them against the prisoner, as if he felt bound to prove the case for the prosecution, nor, on the other, out of a mistaken compassion, giving explanations of them quite at variance with common sense. He should endeavour, in fact, to tell the truth, the whole truth, and nothing but the truth, though sometimes the mode in which counsel examine or cross-examine may render it difficult to do this; and cases have even occurred where it seemed, from the questions of the presiding judge, that he wished the medical witness to go further in his deductions than the facts seemed to warrant. In cases of supposed rape this caution is especially needed, as otherwise serious injustice may be done. Where the girl in such a case has reached the age (16)

1 The form used is one approved by Dr. Danford Thomas, Coroner for Central Middlesex, and can be had at the Coroner's Office, 87 Euston Road, London. 
at which her consent is valid, we naturally expect to find some evidence of a struggle, if a rape has been effected against her will; and if there are no marks on her limbs or clothes, and yet we find that penetration has taken place, we are bound, if asked, to say that we find no evidence of resistance, unless she is unusually weak or small for her age.

On the other hand, in a case of supposed infanticide, where a servant-girl had been secretly confined, and the child's body was found with its head smashed in, it seemed absurd for the medical witness to suggest that the injury might have been done by the girl being delivered in the upright position, and the child during birth having fallen on the floor. Had he waited for the defending counsel to ask if such a thing were possible, his evidence would have had more weight with judge and jury. As it was, counsel on neither side thought the suggestion worth discussing. Another point in connection with such cases is, that no medical man called in either by the police, by magistrates, or by the patient's employer, ought, on any account, to examine a woman, in order to ascertain whether she is pregnant or has been recently confined, without first obtaining her own consent to such examination in the presence of a witness - no other person whatever, except in the case of minors, the parents, having power to authorise it. We lay stress on this point, because we have known well-qualified and experienced men make the mistake, with disagreeable results to themselves.

3. The following are illustrative cases of the penalties and annoyances which medical practitioners may incur, and which might have been easily avoided by exercising reasonable caution and ordinary common sense :-

In 1861 a surgeon practising in Cheshire was verbally requested by the county coroner and by an inspector of police, who accompanied him to the house, to examine a respectable married woman, in order to ascertain whether she had been recently delivered, the reason being that the dead body of a child had been found near the house! The surgeon told the woman that she was suspected of having had a child, that he had come to examine her by the authority of the law, and that she must submit. She refused at first, and proposed to send for a medical man whom she knew. Had the surgeon consented to this very reasonable proposal, all might have been well. But he refused to wait, insisted upon examining her, and did so. The result was negative, there not being the slightest indication of recent delivery. An action for damages followed, ending in a verdict of $£ 200$ damages, and the practical ruin of the unfortunate surgeon.

One of the writers was present in court, and remembers perfectly the case, which naturally excited much interest in medical circles, and probably acted as a warning.

But only for a time. Eight years later, a surgeon and inspector of police insisted upon the examination of two women, mother and daughter, in order to determine whether either of them had been lately delivered of a child ; this was against their consent, and in the absence 
of the husband and father, who brought an action against the inspector and surgeon, and recovered $£ 20$ damages and costs against each.

And two years later the matter assumed a tragic form. Two medical men, armed with a written order from the coroner, proceeded to a rectory to examine a young lady, sister of the rector, to ascertain if she had recently had a child. She refused to see them, and subsequently destroyed herself. Naturally enough the medical men justified themselves by the written order of the coroner, as the surgeon previously referred to did with regard to his verbal order. But even in those days medical men knew that the coroner's functions relate rather to the dead than to the living.

That a coroner had power to order a post-mortem examination, to summon a jury, to enter the house where any dead body, for the time being his property, was lying, and to summon witnessesthese were facts well known. But to order the examination of a living woman's person was, to say the least, unusual and singular. No counsel nor solicitor, even at that time, could have been absolutely certain of the legality of such an order, and certainly no blame, no action for damages, and no tragedy such as the one above related, would have followed the refusal of the surgeon to obey any such order. But more remains. For the present, it is sufficient to state that for a coroner to issue such an order is grossly illegal, and therefore it would be equally so to obey it.

But though the coroner has no right to issue an order for the examination of a woman suspected of child murder, and supposed to have been recently delivered, it was supposed that magistrates had such right, and even the late learned and experienced medical jurist, Dr. Tidy, implied in his Legal Medicine, vol. ii. p. 145, that a magistrate had power to give a written order for such examination in the case of a prisoner under his control. But the case of Agnew $v$. Jobson has disproved this. In that case the defendant, a medical magistrate, acting in his magisterial capacity, did give such an order to a physician and surgeon to examine a woman suspected of infanticide ; the result being, an action for damages against all three, and a verdict for $£ 50$ damages; the fact being that no magistrate has any right to issue such an order.

These facts are very important, both to students and young medical practitioners, to whom medico-legal work possesses great attractions. They are too apt to obey with alacrity the order to attend a coroner or magistrate's court (until the novelty has worn off), and they are apt to assume that any order from a legal or even police official may be safely obeyed. The foregoing statements ought to dispel such illusions. The law of England assumes the innocence of any suspected person until the guilt has been proved. No police officer has a right to question any prisoner, without first cautioning him that what he states will be written down, and may be used against him. Every magistrate, in committing a prisoner for trial, addresses an even 
stronger caution, the principle being that no accused person can be called upon to criminate himself or herself. This is only reasonable, and common sense.

4. So far we have dealt with the medical examination of females. But any surgeon, and especially police surgeons, may be asked to examine a male prisoner charged with any offence, especially rape, criminal assault, or unnatural crime. Speaking generally, a surgeon has a perfect right to use his eyes and to notice anything that he sees on a prisoner's face, hands, or clothes. But he has no right to order a prisoner to undress, nor to examine his person without first obtaining his consent in the presence of one or more witnesses. This consent must be absolute and indisputable. $\mathrm{He}$ must be given clearly to understand that though a prisoner in a police station, and surrounded by police officials, he is perfectly free, so far as his person is concerned, and cannot be examined unless he freely consents. He should also be cautioned that the result of the examination may be in his favour or against him, and that in either case the surgeon will be bound to state the truth. If, aiter this, he consents, the surgeon's course is clear. All these cautions are absolutely necessary to prevent injustice. For instance, a man might be charged with rape. The female charging him might be suffering from a purulent discharge, or from syphilis. $\mathrm{He}$, though perfectly innocent of the charge, might be suffering from gonorrhea or syphilis. An examination of his person might furnish damning and yet false evidence against him. A refusal to submit to examination does not imply guilt, any more than does consent imply innocence.

One more very important duty asked of medical practitioners in family practice may be noticed here, and may be illustrated by the following case :-

A lady returning home from a holiday was informed by the charwoman whom she employed that one of her servants was pregnant. Acting on the feminine and virtuous impulse of the moment, this good lady told the servant what she had heard, and, in spite of her denials, ordered her to pack up, saying that the doctor was coming to examine her. The surgeon who came acted most unwisely and improperly, examining the girl in her bedroom without any witnesses, and in spite of her protests. The result was negative, there being no indication of pregnancy whatever. An action followed, with appeals to the highest court, and though the defendants, i.e. the master, mistress, and surgeon, won all round, they were put to almost ruinous costs, as well as great annoyance.

The warning here is obvious. If a servant is suspected of being pregnant, a medical man may, by the exercise of a little tact, often satisfy himself of the truth or error of the charge, without arousing any suspicion that such has been made. But if it be deemed necessary to examine the breasts and the abdomen, it is needless to add that this ought to be done in the presence of a female witness, preferably a married woman. 